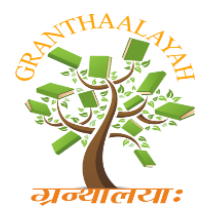

INTERNATIONAL JOURNAL OF RESEARCH GRANTHAALAYAH

A knowledge Repository

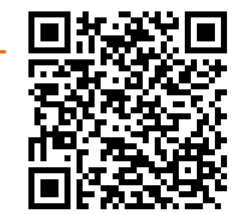

Science

\title{
THE STUDY OF EGG QUALITY ON CHICKEN VILLAGE IN CHELLIYA DISTRICT WESTERN SHOA, ETHIOPIA
}

\author{
Getachew Bekele Fereja ${ }^{* 1}$, Bikila Negari ${ }^{2}$, Mengistu Urge ${ }^{3}$, Negassi Ameha ${ }^{4}$ \\ ${ }^{* 1}$ Departement of Animal Science, College of Agriculture and Natural Resources, Gambella \\ University, ETHIOPIA \\ ${ }^{2,3,4}$ School of Animal and Range Sciences, Haramaya University, Dire dewa, ETHIOPIA
}

\begin{abstract}
Assessment of village chicken egg quality parameters were conducted in two agro-ecology and eight rural kebeles, in Chelliya district. A total of 120 households were participated in the survey. Eggs were collected from 15 households for determination of egg quality parameters and two eggs were collected each from indigenous, cross breed and exotic, hence ten eggs were collected from each breed. Total of 240 eggs were used for this experiments. The objectives this study was to assess some quality parameters of eggs produced under scavenging production system. The exotics breed had higher egg production performance $(198.80+10.45)$ than indigenous breed (155.2+10.45). The price of egg, pullet, and laying hen during the study period were 1.91 $\pm 0.02,38.43 \pm 0.87$, and $44.24 \pm 0.83$ Birr, respectively. The average Hough unit was 69.13, 74.50, and 82.63 (SE=2.21) local, crossbreed and exotics, respectively and 74.17 $\mathrm{mm}$ for highland and $76.67 \mathrm{~mm}$ for midland $(S E=1.81)$. Average yolk color was 10.69, 10.35, 8.62 (SE=0.24) and average yolk index 354.93, 358.07, 377.13(SE=5.96) for local, crossbreed and exotics and also 9.58, 10.20 $\mathrm{SE}=0.19$ and 357.05, 369.70(SE=4.87) in midland and highland. Except for Hough unit, the highland had higher mean values for these parameters than the eggs collected from midland. Similarly, exotic breed has higher mean values than that of indigenous and cross breed eggs, except Shell Thickness and Yolk Color. In summary there is a need for improvement in egg quality of the cross breeds and indigenous breeds.
\end{abstract}

Keywords:

Yolk, albumen, egg quality, indigenous.

Cite This Article: Getachew Bekele Fereja, Bikila Negari, Mengistu Urge, and Negassi Ameha, “THE STUDY OF EGG QUALITY ON CHICKEN VILLAGE IN CHELLIYA DISTRICT WESTERN SHOA, ETHIOPIA" International Journal of Research - Granthaalayah, Vol. 4, No. 2 (2016): 46-51.

\section{INTRODUCTION}

Animal production in general and chickens in particular play important socioeconomic roles in developing countries (Alders, 2004; Salam, 2005). Population growth, urbanization and rising 
income in many parts of the developing world have caused a growing demand for food of animal origin. According to the World Watch Institute (2011), 74\% of the world's poultry meat, and $68 \%$ of eggs are produced in ways that are described as 'intensive' in the year 2011. In many parts of the world, poultry are kept as scavengers in and around the residence areas of the human beings. Almost all rural and urban families in developing countries keep a small flock of free range chickens (Jens et al., 2004). Village chickens are also an integrated component of nearly all-rural, many peri-urban and some urban households and accounts for more than $60 \%$ of the total national chicken population in most African countries (Sonaiya, 2004). The local chicken ecotypes remain predominant in African villages.

Moreover, the rural poultry in the country represents a significant part of the national economy in general and the rural economy in particular and contributes $98.5 \%$ and $99.2 \%$ of the national egg and chicken meat production, respectively (Tadelle and Ogle, 1996; Aberra, 2000). However, the economic contribution of the sector is not still proportional to the huge chicken numbers, which is an attribute of the presence of many production, reproduction and marketing constraints. In this regard, the available literature tends to indicate that the per capita poultry and poultry product consumption in Ethiopia is one of the lowest in the world (Alemu, 1995). The indigenous flocks are considered to be very poor in egg production performance, feed problem, health aspects, attributed to the low genetic potential (slow growth rate and late sexual maturity, and broodiness for an extended period).

To date, there were no any detailed studies conducted in Chelliya that targeted comprehensive description of the prevailing village chicken production and marketing practices, assessment of internal and external quality of marketable eggs, identification of major production and marketing constraints as well as assessment of appropriate technological interventions that could be affordable to the resource-poor in relation to the current chicken production practices in the study area. Therefore, this study was conducted with the objectives to assess some quality parameters of eggs produced under scavenging production system.

\section{MATERIALS AND METHODS}

\section{DESCRIPTION OF THE STUDY AREA}

The study was conducted at Chelliya District, West Shewa Zone of Oromia National Regional State. Chelliya District is located in Western part of the country. The area is located at $175 \mathrm{~km}$ Western of Addis Ababa on the main highway to Nekemte. It is situated at an altitudinal range of 1700-3060 m.a.s.l. The north-western part of the District is covered with hilly slopes and mountainous rising to an elevation of about 3060 m.a.s.l. at Tullu Jarso Mountain (Endalew, 2007). The study District lies approximately between $19^{\circ} 02^{\prime}$ and $9^{\circ} 1^{\prime}$ 'North ' latitudes and $37^{\circ} 25^{\prime}$ and $37^{\circ} 16^{\prime}$ longitudes East of Prime Meridian. The study area has one cropping cycle per year, and few irrigation activities, having a temperature range of $10-25^{\circ} \mathrm{C}$. The farming system was characterized by crop-livestock production systems.. 


\section{DATA COLLECTION}

From the four RKs purposively selected from each agro-ecology, 15 households who owned flock of indigenous, cross bred and exotic of Isa Brown (pure breed ) chicken were selected for the interview (survey part of the study). A rapid field survey was conducted before the main survey work to know the distribution and contribution of exotic chicken breeds and existing local strain in the rural households. For the interview, a semi-structured questionnaire were prepared, pretested on two non-random sampled households from each study sites during the rapid field survey and the interview was conducted with the household head.

\section{EGGS QUALITY PARAMETERS}

Following the survey, eggs laid during one week was collected from 15 households involved that were in the interview from each RK and transported to Haramaya University for quality analysis. The eggs were labeled with the code given to the RKs at the time of collection from the respective households. Eggs from pure indigenous, exotic or cross bred hens were identified at collection. Both internal and external egg quality parameters were measured on all eggs acquired from each households selected for this purpose and the eight RKs. A total of 240 eggs were acquired for this experiment and two eggs were collected from each household. Therefore, from each breed of chicken ten eggs were collected from indigenous, crossbreed and exotic (Isa brown), respectively.

Egg quality was assessed in terms of egg weight, shell thickness, yolk color, albumen height, yolk index and Haugh Unit Score (HUS). Egg weight was measure by taking the individual egg and putting on the sensitive balance and takes the weight measure. The egg shell thickness was measured on eggs sample taken at three sites, at equator, from the blunt and pointed end of each of the RKs eggs using a micrometer gauge. The average of the three measurements was taken as thickness of each egg and RKs values were computed as average of the eggs (Ajuwon et al., 2002).

The albumen of the broken eggs was carefully separated from the yolk. Tripod micrometer was used to measure the albumen height. Albumen weight was measured using sensitive balance. Albumen and yolk diameters were measured by ruler after breaking the eggs on flat tray. The eight RKs eggs sample were individually weighted, marked and broken on flat tray and the height of the thick albumen of each egg was measured with a tripod micrometer and the average Huagh Unit value for each RK was calculated by using the formula given by Stadelman and Cotterill (1986). Yolk color was measured after yolk membrane was removed, and yolk sample was taken on pieces of white paper and computed by Roche fan measurement strips which have 1-15 strips from pale to orange yellow.

\section{STATISTICAL ANALYSIS}

All data collected were checked for any eggs and corrected and coded. Data from the survey were analyzed using statistical package for social science (SPSS) version 15.0 for windows and Mean differences as applicable was separated using LSD. The mean statistics (mean, SE) for continuous variables obtained from the survey were subjected to analysis of variance (ANOVA) 
using the general linear model procedure of SPSS. Both internal and external egg quality parameters were analyzed by SAS (2002).

\section{RESULTS AND DISCUSSION}

\section{EGG QUALITY PARAMETERS}

\section{INTERNAL AND EXTERNAL EGG QUALITY PARAMETERS}

The average weight of eggs collected from different sources was $51.17 \pm 1.03 \mathrm{~g}$. The result also revealed that there was significant difference in average weight of eggs collected from different sources of the study area. Most of these changes in egg quality in terms of albumen height, HU, and yolk index, could be attributed to water loss by evaporation through the pores in the shell and the escape of carbon dioxide from albumen, the net effect of which results in progressive loss in egg weight and a continual decline in egg quality (Samli et al., 2005). Based on the result of this study, the average values of the egg weight of Highland was significantly higher than that of midland (Table 1) indicating quality deterioration as a result of longer period of storage at relatively higher temperature.

This result is similar to that of Samli et al. (2005), who suggested that HU and egg weight is the parameter greatly influenced by egg storage period and temperature. According to Samli et al. (2005), egg storage period of more than 10 days at $29^{\circ} \mathrm{C}$ brought egg weight losses of $1.94 \mathrm{~g}$. The result was similar with that reported by Hallima (2007), for eggs collected from seven chicken ecotypes of North-West Amhara. Teketel (1986) also reported an average egg weight of 46g for Ethiopian local breed chicken. The average egg weight $(51.17 \pm 1.03 \mathrm{~g})$ obtained from this study was lower than that reported by Halima (2007) for RIR chicken breed eggs (53.4g), but higher than the value of 35-39g reported by Ahmed (1994) for Bangladesh indigenous scavenging chicken eggs.

The result of the current study showed no significant difference between eggs collected from different sources of the study area, with respect to average eggshell thickness. The result obtained for shell thickness was lower than the value of $0.71 \mathrm{~mm}$ and $0.69 \mathrm{~mm}$ reported by Halima (2007) for eggs collected from intensively managed local chicken ecotypes of NorthWest Amhara and RIR chicken breeds, respectively. Similarly, Teketel (1986) reported an average egg shell thickness of $0.35 \mathrm{~mm}$ for Ethiopian local breed chicken eggs. Asuquo et al. (1992) also reported an average egg shell thickness of $0.30 \mathrm{~mm}$ and $0.35 \mathrm{~mm}$ for Nigerian local breeds and Isa -Brown breed chicken eggs, respectively.

The average Haugh unit value obtained in this study was higher than the value of 61.1 reported by Halima (2007) for eggs collected from local chicken ecotypes of North-West Amhara and lower than that recorded by the same author for eggs collected from intensively managed RIR chicken breeds (81.0). Asuquo et al. (1992) also reported higher Hough unit values of 79.8 and 89.9 for eggs collected from Nigerian local hens and Isa-Brown chicken breeds, respectively.

The mean yolk color result of the two agro ecology obtained from this study was higher than that reported by Halima (2007) for eggs collected from intensively managed local hens (3.48) of 
North-West Amhara and RIR chicken breed hens (4.0), respectively. Pavlovski et al. (1981) also reported that the yolk color score of free range local hens was higher compared to eggs collected from hens managed under intensive chicken management condition. In general there was significant difference between highland and midland eggs collected from the farmers in egg weight and Yolk Color. In all the parameters, highland had higher mean values than that of the midland eggs collected except Hough unit and also exotic breed have higher mean values than that of indigenous and cross breed eggs collected except Shell Thickness and Yolk Color.

Table 1: Effect of breed and agro-ecology on external and internal quality (Mean \pm SE) eggs produced by village chicken in Chelliya districts ( 80 for each breeds, Total eggs used=240)

\begin{tabular}{|c|c|c|c|c|c|c|}
\hline \multirow{3}{*}{$\begin{array}{l}\text { Parameter } \\
\mathrm{s}\end{array}$} & \multicolumn{2}{|c|}{ Agro Ecology } & \multicolumn{3}{|l|}{ Breed } & \multirow{3}{*}{$\begin{array}{l}\text { Agro } \\
\text { ecolog } \\
\mathrm{y} \quad \mathrm{x} \\
\text { breed }\end{array}$} \\
\hline & \multirow[t]{2}{*}{ Highland } & \multirow[t]{2}{*}{ Midland } & \multirow[t]{2}{*}{ Indigenous } & \multirow[t]{2}{*}{ Cross Breed } & \multirow[t]{2}{*}{ Exotic } & \\
\hline & & & & & & \\
\hline EW (g) & $\underset{\mathrm{a}}{53.52 \pm 1.03}$ & $\begin{array}{l}48.82 \pm 1.03 \\
\mathrm{~b}\end{array}$ & $41.13 \pm 1.26^{b}$ & $54.46 \pm 1.26^{\mathrm{a}}$ & $57.92 \pm 1.26^{\mathrm{a}}$ & - \\
\hline $\begin{array}{l}\text { SHT } \\
(\mathrm{mm})\end{array}$ & $0.28 \pm 0.02$ & $0.27 \pm 0.02$ & $0.27 \pm 0.02$ & $0.29 \pm 0.02$ & $0.27 \pm 0.02$ & - \\
\hline YC (1-15) & $\underset{\mathrm{a}}{10.20 \pm 0.19}$ & $9.58 \pm 0.19^{b}$ & $10.69 \pm 0.24^{\mathrm{a}}$ & $10.35 \pm 0.24^{\mathrm{a}}$ & $8.62 \pm 0.24^{b}$ & $* * *$ \\
\hline $\mathrm{AH}(\mathrm{mm})$ & $5.62 \pm 0.28$ & $5.53 \pm 0.28$ & $4.37 \pm 0.34^{\mathrm{c}}$ & $5.42 \pm 0.34^{\mathrm{b}}$ & $6.94 \pm 0.34^{\mathrm{a}}$ & - \\
\hline YI (\%) & $369.7 \pm 4.87$ & $357.1 \pm 4.87$ & $\underset{\mathrm{b}}{354.93 \pm 5.96}$ & $\begin{array}{l}358.07 \pm 5.9 \\
6^{b}\end{array}$ & $\underset{\mathrm{a}}{377.13 \pm 5.96}$ & - \\
\hline HU (g) & $74.17 \pm 1.81$ & $76.67 \pm 1.81$ & $69.13 \pm 2.21^{\mathrm{b}}$ & $74.50 \pm 2.21^{\mathrm{b}}$ & $82.63 \pm 2.21^{\mathrm{a}}$ & - \\
\hline
\end{tabular}

Means within a row under the same heading with different superscript differ significantly between the two agro ecologies and breeds $(\mathrm{P}<0.05)$; EW=Egg Weight; SHT =Shell Thickness; $\mathrm{YC}=$ Yolk Color; $\mathrm{AH}=$ Albumen height; $\mathrm{YI}=$ yolk index; $\mathrm{HU}=$ Hough unit; $\mathrm{SE}=$ Standard Error; $\mathrm{mm}=$ millimeters; $\mathrm{g}=$ gram; $\%=$ percent; *** significant at $\mathrm{P}<0.001$.

\section{CONCLUSION}

The study was conducted in eight RKs located in midland and highland altitude in Chelliya districts, Western Shewa, Ethiopia, with the objectives of assessing some quality parameters of eggs produced under scavenging production system. The four RKs in each of the agro ecology were purposively selected based on poultry population and accessibility of the kebeles. Fifteen households were purposively selected from each of the RKs for the survey part of the study.

Regarding egg weight, the result of the current study showed that the average weight of eggs collected from different sources of the study district was $51.17 \pm 1.03 \mathrm{~g}$ and the shell thickness was found to be $0.27 \pm 0.02$ and $0.28 \pm 0.02 \mathrm{~mm}$ for midland and highland, respectively. The average albumen height of eggs was $4.37 \pm 0.34 \mathrm{~mm}, 5.42 \pm 0.34 \mathrm{~mm}, 6.94 \pm 0.34 \mathrm{~mm}$, local, crossbreed and exotics, respectively. The average Hough unit was calculated to be $69.13 \pm 2.21,74.50 \pm 2.21$ and, $82.63 \pm 2.21$ local, crossbreed and exotics, respectively and also the highland $74.17 \pm 1.81 \mathrm{~mm}$ and for midland $76.67 \pm 1.81 \mathrm{~mm}$, respectively. Average yolk color was $10.69 \pm 0.24,10.35 \pm 0.24$, $8.62 \pm 0.24$ and average yolk index $354.93 \pm 5.96,358.07 \pm 5.96,377.13 \pm 5.96$ for local, crossbreed and exotics and also 9.58 $\pm 0.19,10.20 \pm 0.19$ and $357.05 \pm 4.87,369.70 \pm 4.87$ in midland and 
highland, respectively. In generally there was a significant difference between highland and midland eggs collected from the farmers in egg weight and Yolk Color. In all the parameters, highland had higher mean values than that of the midland eggs collected except Hough unit and also exotic breed higher mean values than that of indigenous and cross breed eggs collected except Shell Thickness and Yolk Color.

\section{REFERENCES}

[1] Aberra Melesse, 2000. Comparative studies on performance and physiological responses of Ethiopian indigenous ("Angete-melata") chicken and their F1 crosses to long term heat stress. PhD Thesis. Martin-Luther University, Halle-Wittenberg, Berlin. pp: 4-5.

[2] Ahmed, N. 1994. Backyard poultry feeding systems in Bangladesh. Asian Livestock, 7: 73-79.

[3] Ajuwon K.M., O.Matanmi and O. C. Daniyan, 2002. Effects of water sources and ascorbic acid supplementation on egg quality and production parameters of laying hens. Livestock Research. For Rural Development No14, volume 6.

[4] Alders, R., 2004. Poultry for profit and pleasure. FAO Diversification Booklet 3. Rome.

[5] Alemu, Y. 1995. Poultry production in Ethiopia. World's poultry science journal, 51:pp197-201.

[6] Asuquo, B.O., B.O. Okon and A.O. Ekong. 1992. Quality parameters of Isa-Brown and Nigerian local chicken eggs. Nigerian Journal Animal Prod (19): 1-5.

[7] Halima Hassen Mogesse, 2007. Phenotypic and genetic characterization of indigenous chicken populations in North-West Ethiopia. PhD Thesis. Submitted to the faculty of natural and agricultural sciences department of animal, wildlife and grassland Sciences, University of the Free State, Bloemfontein, South Africa.

[8] Jens Christian R, Anders P, Charlotte V, Ainsh MC, Lone F (2004). Keeping Village Poultry, A technical manual for small-scale poultry production. Copenhagen, Denmark.

[9] Pavlovski, Z., B. Hopic, S.Vracar and B.Masic. 1994. Effect of housing system on internal egg quality traits in small layer flocks. Biotehnologija u stocarstvu, Yugoslavia, 10:37-43.

[10] Samli, Kul, and Ibrahim, Seker, 2005. Phenotypic Correlations between Some External and Internal Egg Quality Traits in the Japanese Quail (Coturnix coturnix japonica). Department of Zootechnia, Faculty of Veterinary Medicine, Firat University, 23119 Elazig, Turkey. Singh, R.A., 1990. Poultry Production. 3rd edition. Kalyani publishers, New Delhi, India.

[11] SAS (statistical analysis system), 2002. SAS, institute Inc, Cary, N c, USA.

[12] Sonaiya E. B. and S. E.J. Swan, 2004. Small-scale poultry production, technical guide manual. FAO Animal Production and Health 1. Food and Agriculture Organization of the United Nations (FAO), Rome.

[13] Stadelman, W.J. and O.J. Cotterill, 1986. Egg Scie and Technology. 4th Edn., Food products press. An Imprint of the Haworth Press. INC. New York London.

[14] Tadelle Dessie and Ogle B., 1996. Studies on poultry production systems in the central highlands of Ethiopia. M.Sc Thesis. Swedish University of Agricultural Sciences. 72 p.

[15] Teketel Fursido, 1986. Studies on the meat production potentials of some local strains of chickens in Ethiopia. PhD. thesis presented to the University Giessen, Germany, pp123126. 